\title{
Application of time series analysis in soil moisture of fixed dune on Korqin Sandy Land, Northern China
}

\author{
Yao S. and Zhao C.* \\ Lanzhou City University, Lanzhou 730070, China \\ Received: 01/07/2020, Accepted: 11/09/2020, Available online: 21/10/2020 \\ *to whom all correspondence should be addressed: e-mail: zhao_chch1978@163.com
}

\section{https://doi.org/10.30955/gnj.003373}

\section{Graphical abstract}

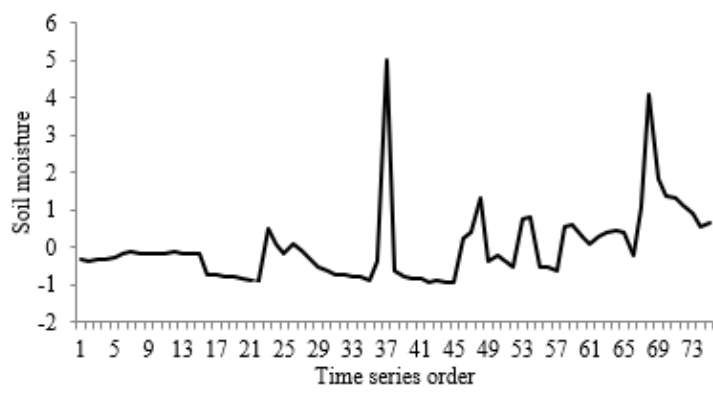

\begin{abstract}
Time series analysis is a very effective method to analyze the dynamic characteristics of soil moisture at long-term scale. In this study, we have used the time series to analyze the relationship between precipitation and soil moisture on fixed dune at different soil depths (from 0 to $120 \mathrm{~cm}$ ) during the growing season (from May to September) of 2006-2010 in Korqin Sandy Land, northern China. The results indicate that: (1) The precipitation is a relatively independent time series and has no obvious autocorrelation. Precipitation in an earlier stage has no obvious effect on the later stage in the growing season. (2) Soil moisture in different soil layers has higher autocorrelation; and the autocorrelation of soil moisture in each soil layer is significantly weakened with the increase in time lag interval. (3) The correlation coefficient between soil moisture and precipitation in each soil layer is higher at the time lag interval of $k=0$; with the increase in soil depth, the correlation is gradually weakened. (4) The maximum correlation coefficients of soil moisture series and precipitation series in different soil depths were obtained at the time lag interval of $k=0$.
\end{abstract}

Keywords: Fixed dune, Korqin Sandy Land, soil moisture, time series analysis, northern China.

\section{Introduction}

Soil moisture is an important component of soil properties and direct impacts on vegetation growth and soil nutrients transforming processes (Letian et al., 2012). It also plays a critical role in understanding various hydrologic processes, such as runoff generation, evapotranspiration, water infiltration, and so on (Hotta et al., 2010; Kim et al., 2011; Puri et al., 2011). The temporal pattern of soil moisture is a key feature of hydrologic interactions with climate (Albertson et al., 2001), and hence, the temporal dynamics of soil moisture has been studied by many researchers (Kuzyakova et al., 2006; Letian et al., 2012; Yao et al., 2013).

Soil moisture status are the main limiting factor for vegetation growth, especially in arid and semi-arid areas (Wang et al., 2015; Yang et al., 2018). Horqin Sand Land is one of China's four major sandy lands (Qadir et al., 2008). The ecological environment here is fragile, and soil moisture is a key factor for the ecosystem stability in the region (Yao et al., 2013). As is well known, due to overgrazing and unsustainable cultivation, this area has become one of the most severely deserted regions in China (Wang et al., 1999; Wang et al., 2016). The soil moisture dynamics and their relationship with precipitation in such dune areas have become one of the most important areas have been paid more attention for research on landsurface processes in arid China (Wang et al., 1999).

Time series analysis is a statistical method of a long series data processing. Based on stochastic process theory and mathematical statistics, this method studies the statistical law followed by stochastic data series, and quantitatively predicts the future development of series (Cryer et al., 2011). Studies have shown that precipitation and soil moisture have a strong correlation in a certain period of time (Jacques et al., 2001). Time series analysis is a very effective method to study the long-term dynamic relationship between soil moisture and precipitation (Zhou et al., 1998), (Shi et al., 2004), and is thus widely used (Ford et al., 2005; Kuzyakova et al., 2006; Letian et al., 2012; Liu et al., 2008; Son et al., 2007; Wang et al., 2007; Wang et al., 2012). Results of these studies show that precipitation series are uncorrelated, and the soil moisture in each soil layer has a high autocorrelation (Shi et al., 2004; Wang et al., 2007; Wang et al., 2012). However, due to the influence of precipitation, evaporation, vegetation, topography, soil characteristics, and the precipitation series method used in synchronization with soil moisture, the study results of different types of land in different study areas are significantly different (Jacques et al., 2001). For example, 
Wang et al. (2007) conducted a time series analysis of soil moisture in red soil slopes, using the soil moisture data monitored once every 5 days and the precipitation data corresponding to the date of soil moisture sampling. Their results show that, the influence of precipitation on soil moisture is gradually weakened with the increase of soil depth, and the precipitation has a greater influence on soil moisture in different soil layers in 1 to 3 days after a precipitation event. Zhou et al. (1998) monitored soil moisture once every 5 days and the precipitation data of the cumulative amount within 5 days of the soil moisture monitoring interval at the Fengqiu Ecological Experimental Station. They suggest that the correlation diagram between the precipitation series and the soil moisture content in different soil layers has a certain periodicity. Wang et al. (2012) sampled the soil moisture once every month and monitored corresponding cumulative monthly precipitation in the mountainous woodlands in Beijing and reported that precipitation was significantly related to soil moisture, however, the correlation between soil moisture and precipitation was different in different soil layers (Mohammad et al., 2019; D’Agata et al., 2020; Achille and Enow, 2020; Abdikadir et al., 2018).

Despite the time series analysis is widely used in soil moisture dynamics and their relationship with precipitation. However, there has been limited use of time series analysis to study soil moisture dynamics and their correlation with precipitation in fixed dunes of Horqin sandy land (Nwankwoala, 2019; Ibrahim et al., 2020; Ch et al., 2018; Siti et al., 2019).

In the present study, we conducted field sampling to measure the soil moisture from May to September in 20062010 at different soil depths. We try to study the correlation between soil moisture and precipitation in fixed dune of Horqin Sandy Land based on the time series analysis. The goals of this study were to (a) analyze the dynamic characteristics of soil moisture time series in fixed dune; (b) explore the interrelation between soil moisture and precipitation. It is expected that these results can provide a theoretical basis and guidance for effective preservation of soil moisture in the region.

\section{Material and methods}

\subsection{Study site description}

The study site is located in the southern part of the Horqin Sand Land in eastern Inner Mongolia, China ( $43^{\circ} 55 \mathrm{~N}, 120^{\circ}$ $42 \mathrm{E}$, elevation approx. $360 \mathrm{~m}$ ). The climate in this area is temperate, semiarid continental monsoonal, receiving an average annual precipitation of $360 \mathrm{~mm}$, with $75 \%$ falling in the growing season (from June to September). The mean annual temperature is $5.8-6.4{ }^{\circ} \mathrm{C}$. The mean annual wind velocity ranges from 3.2 to $4.1 \mathrm{~m} \cdot \mathrm{s}^{-1}$. The topography is characterized by dunes and inter-dune lowlands. The soils are sandy and loose in structure. The geomorphological types in the region are characterized by fixed dunes, mobile dunes, and uneven sandy lands with varying areas.

\subsection{Data collection}

The sample plot $\left(42^{\circ} 939 \mathrm{~N}, 120^{\circ} 692 \mathrm{E}\right.$, elevation approx. $368 \mathrm{~m}$ ) is a long-term soil moisture observation field for fixed dunes at the Naiman Desertification Research Station. The main vegetations were Artemisia scoparia and Setarria viridis, and the vegetation coverage of the sample plot is $80 \%$, and grazing has been prohibited for 30 years within the enclosed space, that is, there has been little or no human disturbance (Yao et al., 2016).

CNC100 neutron moisture meter (Beijing) was employed for determination of soil moisture. Three neutron moisture meters at the depth of $2 \mathrm{~m}$ were buried at an equal interval for regular observation of soil moisture at the depth of 0 $120 \mathrm{~cm}$ in fixed dune. From early May to the end of September in each year, soil moisture was determined once every 10 days for 5 consecutive years (2006-2010), and the measurement was repeated three times every time. The measurement values of the 3 neutron moisture meters calibrated by the traditional drying method were used to calculate the average moisture for analysis.

The daily precipitation during the same period was provided by the Naiman Desertification Research Station weather station. Since the soil moisture was monitored once every 10 days based on existing research methods (Shi et al., 2004; Wang et al., 2007; Wang et al., 2012), the synchronizes precipitation time series was obtained by the cumulative precipitation within 10 days of each soilmoisture monitoring time interval in this paper.

\subsubsection{Time series analysis}

The autocorrelation coefficient $r_{k}$ of the time series $X$ reflects the degree of correlation between the observed value $X_{t}$ at time point $t$ and the observed value $X_{t-k}$ at the time lag interval $k$, and is expressed as follows:

$$
r_{k}=\frac{\sum_{t=1}^{N}\left(X_{t}-\bar{X}\right)\left(X_{t-k}-\bar{X}\right)}{\sum_{t=1}^{N}\left(X_{t}-\bar{X}\right)^{2}}, k=0,1,2, \ldots
$$

where, $N$ is the total number of time series observations, and $N=75$ in this paper; $\bar{X}$ is the average value of the series $X$.

Whether or not the sampling scales are the same and the variability is similar, the correlation between the two-time series can be reflected by the correlation coefficient as long as the two series are synchronized. If their sampling intervals are the same, the cross-correlation coefficient $\phi_{X Y}$ of the stationary time series $X$ and $Y$ with $\mathrm{N}$ pairs of observed values at the time lag interval $k$ is calculated by:

$$
\phi_{X Y}=\frac{\omega_{X Y}(k)}{\left[\omega_{X X}(0) \omega_{Y Y}(0)\right]^{1 / 2}}=\frac{\omega_{X Y}(k)}{\sigma_{X} \sigma_{Y}} .
$$

where, $\omega_{x x}(0)$ and $\omega_{Y Y}(0)$ represent the variance of series $X$ and $Y$ respectively; $\sigma_{x}, \sigma_{Y}$ represent the standard deviation of the series $X$ and $Y$, respectively; and $\omega_{X Y}(k)$ is the crosscovariance value of the series $X$ and $Y$ in the case of time lag interval $k$, and is represented by:

$$
\omega_{X Y}(k)=\sum_{t=1}^{N-k}\left(X_{t}-\bar{X}\right)\left(Y_{t+k}-\bar{Y}\right) .
$$


where, $\bar{Y}$ is the average value of series $Y ; Y_{t+k}$ represent the value of time series $Y$ at time lag interval $k(k=0,1,2, \ldots)$.

\subsubsection{Data processing}

The original data was standardized in order to improve data computing accuracy. The formula for data standardization is as follows:

$$
X_{t}^{*}=\frac{X_{t}-\bar{X}}{\sigma} \text {. }
$$

where, $X_{t}, X_{t}^{*}$ refer to the original data and the standardized data of the series $X$ at the time point $t$, respectively, and $\bar{X}, \sigma$ refer to the average value and standard deviation of the original data of the series $X$, respectively.
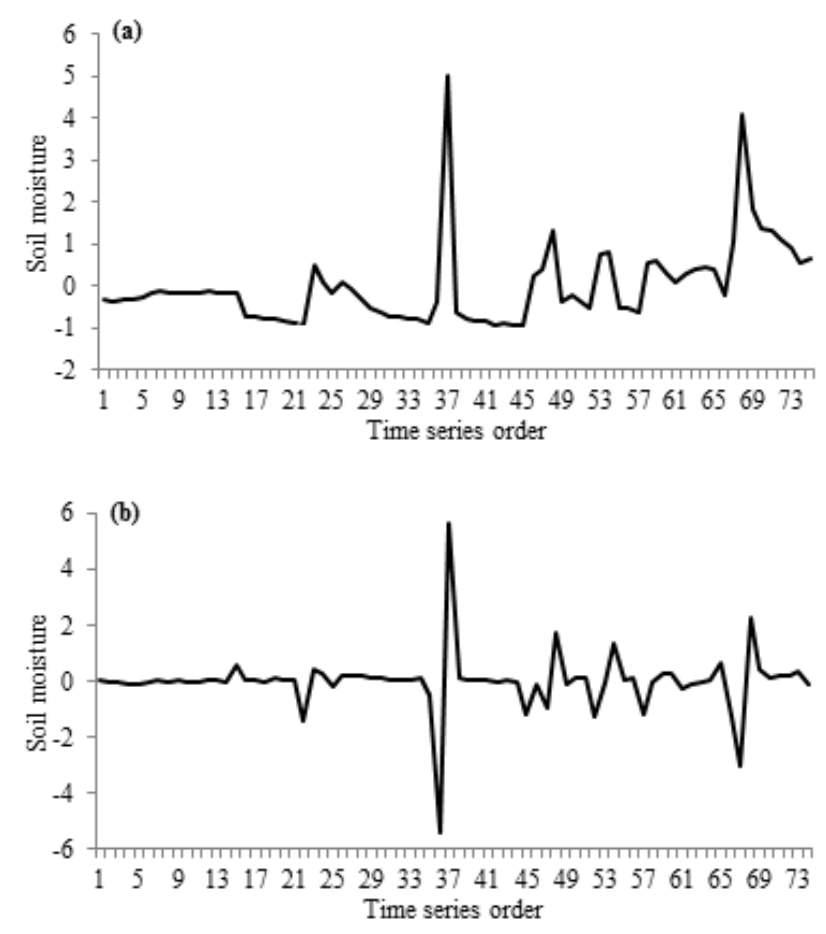

Figure 1. Soil moisture sequence of $60-80 \mathrm{~cm}$ after standardized

(a) and first-order difference based on the standardized (b)

\subsection{Data stationarity test}

Since data used for time series analysis must satisfy the requirement of stationarity, i.e. the autocorrelation coefficient of the series is only related to the time interval, and is independent of its time point, that is, the average value of the series does not change with time. However, most time series in nature do not meet the requirements of stationarity (Li et al., 2013).

In fact, differencing can be used to make non-stationary time series stationary after standardization, the commonly used first-differencing formula $X_{t}^{\#}=X_{t}-X_{t-1}$, where, $X_{t}, X_{t}^{\#}$ denote the original data and the first-differencing data of the series $X$ at the time point $t$.

After the first-order differencing time series of soil moisture in different soil layers in the fixed dunes undergo standardized, it was found that the soil moisture time series of each soil layer met the requirements of stationarity (Liu, 2018).

Taking the $60-80 \mathrm{~cm}$ layer as an example, based on the soil moisture series diagram after standardization (Figure 1(a)) and after standardization and then first-order differencing (Figure 1(b)), it can be seen that after standardization, the soil moisture series is non-stationary, but after undergoing first-order differencing, the soil moisture series diagram satisfies the stationarity requirements.

\section{Results and discussion}

\subsection{Autocorrelation analysis of time series}

By analyzing the autocorrelation of precipitation series (Table 1), it can be seen that the autocorrelation coefficients of precipitation are all small at different time lag intervals, indicating that there is no obvious autocorrelation in the precipitation series. This is consistent with existing study results (Shi et al., 2004; Wang et al., 2007; Wang et al., 2012), primarily because the precipitation series is a relatively independent time series, and the precipitation in the earlier stage has no significant effect on the later stage.

Table 1. Autocorrelation coefficients of precipitation at the different time lag interval

\begin{tabular}{cccccccc}
\hline Time lag interval & $\mathbf{1}$ & $\mathbf{2}$ & $\mathbf{3}$ & $\mathbf{4}$ & $\mathbf{5}$ & $\mathbf{6}$ & $\mathbf{7}$ \\
\hline $\begin{array}{c}\text { Autocorrelation } \\
\text { coefficients }\end{array}$ & 0.047 & -0.056 & 0.085 & -0.074 & -0.141 & -0.101 & -0.077 \\
\hline
\end{tabular}

Based on the autocorrelation analysis of the soil moisture time series after first-order differencing in different soil layers of fixed dunes (Table 2), it can be found that the soil moisture in each soil layer has high autocorrelation (autocorrelation coefficients are all above 0.37 ) at the first time lag interval $k=1$ (i.e., 10 days), indicating that the soil moisture in the fixed dune is most affected by its value of nearly 10 days (Khan et al., 2017). The autocorrelation of soil moisture is smaller in the $40-100 \mathrm{~cm}$ layer, and larger in the $0-40 \mathrm{~cm}$ and $100-120 \mathrm{~cm}$ layers, indicating that the soil moisture in the $40-100 \mathrm{~cm}$ layer is greatly affected by external environment. This is somewhat different from related research results. For example, Liu et al. (2008) analyzed soil moisture in the forests in the red soil zone of Jiangxi, and showed that soil moisture autocorrelation gradually increases with the increase in soil depth. Wang et al. (2012) and Shi et al. (2004) report that the soil moisture autocorrelation coefficient is the largest in the $20-40 \mathrm{~cm}$ soil layer. In fact, the unsaturated flow of soil moisture is a long-term, continuous and slow process. Therefore, soil moisture in the earlier stage will have a certain influence in the later stage. However, due to different study zones, vegetation, soil textures, meteorological elements, and soil moisture monitoring time intervals, the results of different land types in different study areas differ extensively (Wang et al., 2007). As the time lag interval increases, the autocorrelation of soil moisture in each soil layer is significantly weakened, which is consistent with existing study results (Wang et al., 2007; Wang et al., 2012). 
Table 2. Autocorrelation coefficients of soil moisture in different soil layer with different lag time interval

\begin{tabular}{|c|c|c|c|c|c|c|}
\hline \multirow{2}{*}{$\begin{array}{l}\text { Lag time } \\
\text { interval }\end{array}$} & \multicolumn{6}{|c|}{ Soil layer $(\mathrm{cm})$} \\
\hline & $0-20$ & $20-40$ & $40-60$ & $60-80$ & $80-100$ & $100-120$ \\
\hline 1 & 0.46 & 0.485 & 0.378 & 0.382 & 0.396 & 0.452 \\
\hline 2 & 0.186 & 0.259 & 0.204 & 0.195 & 0.244 & 0.291 \\
\hline 3 & 0.135 & 0.134 & 0.099 & 0.153 & 0.194 & 0.228 \\
\hline 4 & 0.101 & 0.097 & 0.065 & 0.135 & 0.175 & 0.205 \\
\hline 5 & 0.118 & 0.089 & 0.061 & 0.133 & 0.184 & 0.209 \\
\hline 6 & 0.198 & 0.082 & 0.040 & 0.094 & 0.141 & 0.162 \\
\hline 7 & 0.199 & 0.017 & -0.008 & 0.039 & 0.078 & 0.096 \\
\hline
\end{tabular}

3.2. Cross-correlation analysis between soil moisture and precipitation

The correlation analysis between the soil moisture series (after undergoing first-order differencing) in different soil layers and the corresponding precipitation series was carried out. From the correlation function diagram (Figure 2 ), it can be seen that at the zeroth time lag interval (i.e. $k=0$ ), the cross-correlation coefficient (CCF) between soil moisture in each soil layer and precipitation is higher. With the increase of soil depth, the correlation between soil moisture and precipitation is gradually weakened, indicating that the effect of precipitation on the soil moisture is higher in the shallow layer than in the deep layer, which is mainly because the vegetation coverage in fixed dunes is lower (Pan et al., 2018), with less blockage of precipitation, and hence, the shallow layer of the soil is recharged by the precipitation faster (Demir et al., 2019; Peng et al., 2018), and the soil moisture in the shallow layer is more susceptible to precipitation than the deep layer. The correlation coefficient between soil moisture of different soil layer and precipitation is gradually weaken with the increasing of time lag interval.

As previous studies shown in the correlation function diagram of precipitation and soil moisture, when the time lag interval $k \geq 0$, the positive correlation coefficient appears at the initial time lag interval. During this time lag interval, the soil moisture begins to respond to precipitation and gradually increases. For the correlation function diagram of precipitation and soil moisture (Figure 2 ), the initial time lag interval is all $k=0$, indicating that the soil moisture in different soil layers of fixed dunes increase rapidly after precipitation (Oyekale, 2017). It can be judged from figure 2 that the period of the correlation function between the precipitation and the soil moisture in the 0-20 $\mathrm{cm}, 20-40 \mathrm{~cm}, 40-60 \mathrm{~cm}, 60-80 \mathrm{~cm}, 80-100 \mathrm{~cm}$, and $100-$ $120 \mathrm{~cm}$ layers is $1.5,2,2,2,1$ and 3.5 time lag intervals (1 time lag is 10 days), indicating that the values of the peaks and valleys on the precipitation diagram are separated by 1.5, 2, 2, 2, 1 and 3.5 time lag intervals, and reflected by corresponding peaks and valleys on the soil moisture dynamic diagram at the soil depth of $20 \mathrm{~cm}, 40 \mathrm{~cm}, 60 \mathrm{~cm}$, $80 \mathrm{~cm}, 100 \mathrm{~cm}$ and $120 \mathrm{~cm}$.
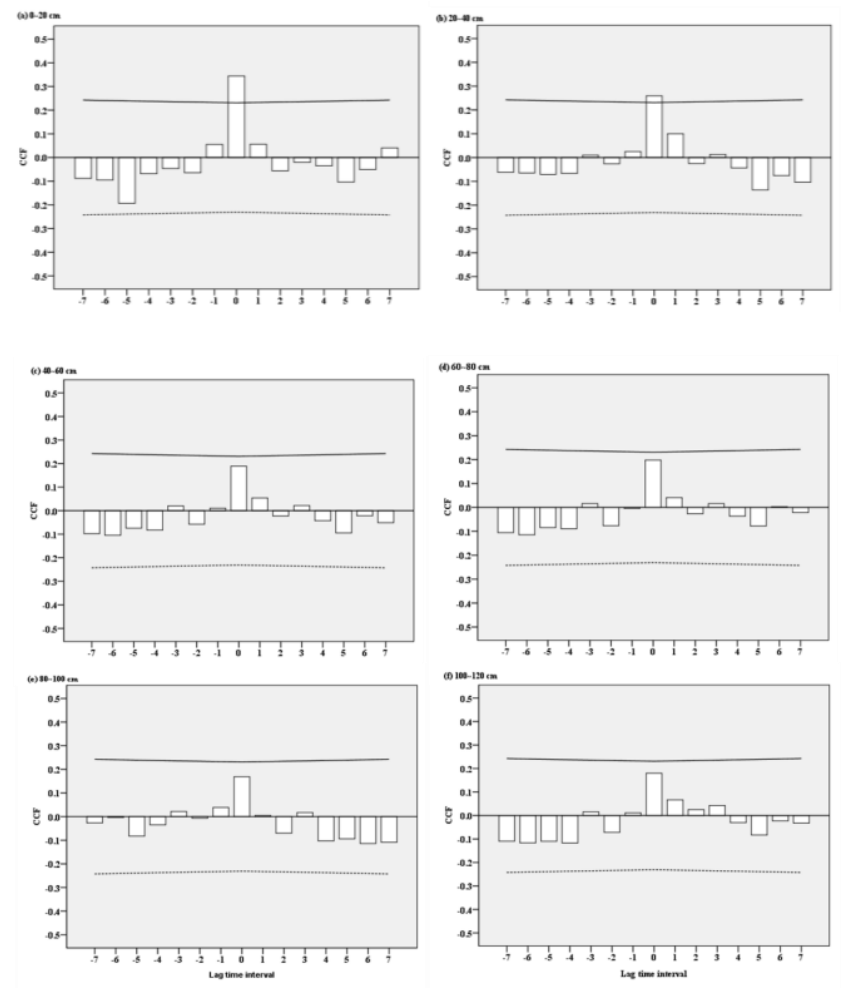

Figure 2. Cross-correlation coefficients (CCF) between soil moisture and precipitation cumulative within $10 \mathrm{~d}$ of each monitoring interval of soil moisture. Note: $\square$ denote CCF, - and ...... denote confident upper bound and confident lower bound, respectively.

In addition, the maximum value of the correlation coefficient between precipitation and soil moisture, together with the corresponding time lag interval, forms a pair of parameters, indicating that the soil moisture reaches the maximum value in response to the precipitation at this time lag interval (Zhou et al., 1998). The maximum correlation coefficient of precipitation and soil moisture series at the soil depth of 20 $\mathrm{cm}, 40 \mathrm{~cm}, 60 \mathrm{~cm}, 80 \mathrm{~cm}, 100 \mathrm{~cm}$ and $120 \mathrm{~cm}$ is $0.34,0.26$, $0.19,0.20,0.17$ and 0.18 , and the corresponding time lag intervals are all $k=0$, indicating that soil moisture in different soil layers of fixed dunes reaches the maximum value soon after a precipitation event. This is different from existing studies. For example, Zhou et al. (1998) showed that there are temporal differences in the response of soil moisture at different depths to precipitation. For instance, the soil moisture at soil depth of $30 \mathrm{~cm}$ and $60 \mathrm{~cm}$ reaches the maximum value at the first time lag interval after a precipitation event, while the soil moisture at soil depth of $90 \mathrm{~cm}$ and $110 \mathrm{~cm}$ reaches the maximum value at 4 and 8 time lag intervals, respectively, where one time lag interval is 5 days (Wang et al., 2017). The main reason for the differences in the study results is due to different study areas, vegetation, soil texture, meteorological elements, and soil moisture monitoring time intervals (Jacques et al., 2001; Wendroth et al., 1999).

\section{Conclusions}

The relationship between precipitation and soil moisture time series on fixed dune at 0 to $120 \mathrm{~cm}$ soil layers from 
May to September of 2006-2010 in Korqin Sandy Land were obtained by the time series analysis. From the study, we can draw some conclusions as follows:

1) The precipitation is a relatively independent time series and has no obvious autocorrelation; Soil moisture in different soil layers of fixed dunes has higher autocorrelation; with the increase in time lag interval, the autocorrelation of soil moisture in each soil layer is significantly weakened.

2) The cross-correlation coefficient between soil moisture and precipitation in each soil layer is higher at the time lag interval $k=1$, and the correlation is gradually weakened with the increase in time lag interval.

3) The soil moisture in different soil layers of fixed dunes increase rapidly after precipitation; And the correlation diagram between the precipitation and soil moisture in different soil layers has a certain periodicity.

4) The maximum correlation coefficients of precipitation and soil moisture series at different soil layers in the fixed dune are all obtained at time lag interval of $k=0$, hence, soil moisture in different soil layers of fixed dunes reaches the maximum value soon after a precipitation event.

\section{Acknowledgments}

This study was supported by the National Natural Science Foundation of China (No. 31960273; No. 41771087). The authors also would like to acknowledge the helpful comments and suggestions from anonymous referees.

\section{References}

Abdikadir A.O., Md S.H. and Mst M.P. (2018), Study on Knowledge, Attitude and Practices Towards the Solid Waste Management in Karan District, Mogadishu Somalia, Environmental Contaminants Reviews, 1(2), 22-26.

Achille D.F. and Enow A.D. (2020), Evaluating the Bidirectional Nexus Between Climate Change and Agriculture from A Global Perspective, Malaysian Journal of Sustainable Agriculture, 4(1), 40-43.

Albertson J.D. and Kiely G. (2001), On the structure of soil moisture time series in the context of land surface models, Journal of Hydrology, 243(1), 101-119.

Ch A., Asma S., Do M.C., Faizan U.H.K., Abdul N., Zia B. and Fariha I. (2018), Study of Spatial and Temporal Variability of Arsenic in Groundwater Due to Drain by Using Gis, Earth Sciences Pakistan, 2(2), 22-24.

Cryer J.D. and Chan K.S. (2011), Time series analysis with applications in R, 2nd ed., China Machine Press, pp. 1-65.

D’Agata C., Diolaiuti G., Maragno D., Smiraglia C. and Pelfini M. (2020), Climate change effects on landscape and environment in glacierized Alpine areas: retreating glaciers and enlarging forelands in the Bernina group (Italy) in the period 19542007, Geology, Ecology, and Landscapes, 4(1), 71-86.

Demir C., Cergibozan R. and Gok A. (2019), Income inequality and $\mathrm{CO}_{2}$ emissions: Empirical evidence from Turkey, Energy \& Environment, 30(3), 444-461.

Ford C.R., Goranson C.E., Mitchell R.J., Will R.E. and Teskey R.O. (2005), Modeling canopy transpiration using time series analysis: A case study illustrating the effect of soil moisture deficit on Pinus taeda, Agricultural and Forest Meteorology, 130(3-4), 0-175.

Hotta N., Tanaka N., Sawano S., Kuraji K., Shiraki K. and Suzuki M. (2010), Changes in groundwater level dynamics after lowimpact forest harvesting in steep, small watersheds, Journal of Hydrology, 385(1-4), 120-131.

Ibrahim S., Magaji J.I and Isa Z. (2020), Simulation of Sediment Yield and Supply on Water Flow in Different Subbasins Of Terengganu Watershed From 1973-2017. Water Conservation and Management, 4(1), 01-06.

Jacques D., Monanv B., Timmerman A. and Feyen J. (2001), Study of time dependency of factors affecting the spatial distribution of soil water content in a field-plot, Physics and Chemistry of the Earth, 26, 629-634.

Khan A.M. and Noor M.J. (2017), Radiocaesium contaminated sites and possible techniques for remediation, Geology, Ecology, and Landscapes, 1(2), 84-94.

Kim S., Sun H. and Jung S. (2011), Configuration of the relationship of soil moistures for vertical soil profiles on a steep hillslope using a vector time series model, Journal of Hydrology, 399(34), 353-363.

Kuzyakova I.F. and Stahr K. (2006), Use of time series analysis and mixed models in studying the long-term dynamics of soil temperature and moisture in a Catena on Loess deposits, Eurasian Soil Science, 39(2), 176-186.

Letian Z., Yuanxin L. and Feng J. (2012), Time series analysis of spatial variability of soil moisture in Loess Hilly Region, Procedia Earth \& Planetary Science, 5, 346-353.

Li Q.L., Ma N. and Fu Z.T. (2013), Comparative analysis of time series non-stationary detection methods, Journal of Beijing University (Natural Science Edition), 49(2), 252-260.

Liu Y.Q., Wang H.S., Guo S.M. and Fu M.N. (2008), Relationships of soil moisture content with precipitation and evaporation in rehabilitated forests in degraded limestone red-soil region of Jiangxi Province, Chinese Journal of Applied Ecology, 19(12), 2588-2592.

Liu Z. (2018), Economic analysis of energy production from coal/biomass upgrading; Part 1: Hydrogen production, Energy Sources Part B-Economics Planning and Policy, 13(2), 132136.

Mohammad K.U.S., Ahmad K.M., Md. Zahurul H., Md. Sahadat H. and Abdullah A.N. (2019), Assessment of Inland Water Quality Parameters of Dhaka City, Bangladesh, Environment \& Ecosystem Science, 3(1), 13-16.

Nwankwoala H.O. (2019), Geoethics As an Emerging Discipline: Perspectives, Ethical Challenges and Prospects, Earth Sciences Malaysia, 3(1), 01-08.

Oyekale A.S. (2017), Cocoa farmers' safety perception and compliance with precautions in the use of pesticides in centre and western Cameroon, Applied Ecology and Environmental Research, 15(3), 205-219.

Pan G., Xu H., Mu B., Ma B. and Yang Y. (2018), A clean approach for potential continuous mass production of high-molecularweight polylactide fibers with fully stereo-complexed crystallites, Journal of Cleaner Production, 176, 151-158.

Peng W., Maleki A., Rosen M.A. and Azarikhah P. (2018), Optimization of a hybrid system for solar-wind-based water desalination by reverse osmosis: Comparison of approaches, Desalination, 442, 16-31. 
Puri S., Stephen H. and Ahmad S. (2011), Relating TRMM precipitation radar land surface backscatter response to soil moisture in the Southern United States, Journal of Hydrology, 402(1-2), 115-125.

Qadir M., Qureshi A.S. and Cheraghi S.A.M. (2008), Extent and characterisation of salt-affected soils in Iran and strategies for their amelioration and management, Land Degradation \& Development, 19(2), 214-227.

Shi H., Liu S.R., Sun P.S. and Li Y.Y. (2004), Time series analysis of soil moisture storage dynamic change in the Chinese pine forest land in hilly region of the Loess Plateau, Journal of mountain science, 22(4). 411-414.

Siti N.M.A., Muhammad F.K., Nik N.N.A. and Mohd F.M. (2019), Distribution Pattern of Rare Earth Elements in Soft Tissue of Saccostrea Cucullata In Terengganu And East Johor Coastal Waters, Journal Clean WAS, 3(2), 14-19.

Son M.N., Kim S.H. and Kim D.H. (2007), Univariate analysis of soil moisture time series for a hillslope located in the KoFlux Gwangneung Supersite, Korean Journal of Agricultural \& Forest Meteorology, 9(2), 88-99.

Wang H.N. and Yu X.X. (2012), Time series analysis of soil water on forest land in Beijing mountain area, Journal of Mountain Science, 30(5), 550-554.

Wang J., Zeng Y., Xu Y. and Feng K. (2017), Analysis of the influence of tunnel portal section construction on slope stability, Geology, Ecology, and Landscapes, 1(1), 5665.Wang Q.X. and Takahashi H. (1999), A land surface water deficit model for an arid and semiarid region: impact of desertification on the water deficit status in the Loess Plateau, China, Journal of Climate, 12(1), 244-257.

Wang S.K., Zuo X.A., Zhao X.Y., Li Y.Q., Zhou X., Lv P., Luo Y.Q. and Yun J.Y. (2016), Responses of soil fungal community to the sandy grassland restoration in Horqin Sandy Land, northern China, Environmental Monitoring \& Assessment, 188(1), 21.

Wang T., Wedin D.A., Franz T.E. and Hiller J. (2015), Effect of vegetation on the temporal stability of soil moisture in grassstabilized semi-arid sand dunes, Journal of Hydrology, 521, 447-459.

Wang X.Y., Chen H.S., Wang K.L., Fu W. and Xie X.L. (2007), Time series analysis of soil water on sloping land in red soil hilly region, Chinese Journal of Applied Ecology, 18(2), 297-302.

Wendroth O., Rogasik H., Koszinski S., Ritsema C.J., Dekker L.W. and Nielsen D.R. (1999), State-space prediction of field-scale soil water content time series in a sandy loam, Soil and Tillage Research, 50(1), 85-93.

Yang T.T., Ala M., Zhang Y.S. and Wu J.B. (2018), Characteristics of soil moisture under different vegetation coverage in Horqin Sandy Land, northern China, Plos One, 1(6), e0198805.

Yao S.X., Zhao C.C., Zhang T.H. and Liu X.P. (2013), Response of the soil water content of mobile dunes to precipitation patterns in Inner Mongolia, northern China, Journal of Arid Environments, 97, 92-98.

Yao S.X., Zhao C.C., Zhang T.H., Wang S.Y. and Li X.D. (2016), Variation of soil moisture at fixed sand dune in the Horqin Sandy Land, Journal of Desert Research, 36(1), 111-117.

Zhou L.Z., Chen Z.X., Zhou L.Y., Xu M.X., Lei Z.D. and Yang S.X. (1998), Time series analysis of soil moisture, Soil, 4, 188-193. 